\title{
Implementing a Clinical Practice Change: Adopting the Nutrition Care Process (NCP)
}

Andrea Carpenter RD ${ }^{1}$, Jordan Mann RD ${ }^{1}$, Dianna Yanchis RD ${ }^{1}$, Alison Campbell RD CDE ${ }^{1}$, Louise Bannister MSc RD ${ }^{1}$, Laura Vresk MSc RD ${ }^{1}$

${ }^{1}$ Department of Clinical Dietetics, The Hospital for Sick Children, Toronto, ON, Canada

\section{Introduction}

- The Nutrition Care Process (NCP) is a four-step model providing a framework to uniform documentation $[1,2]$
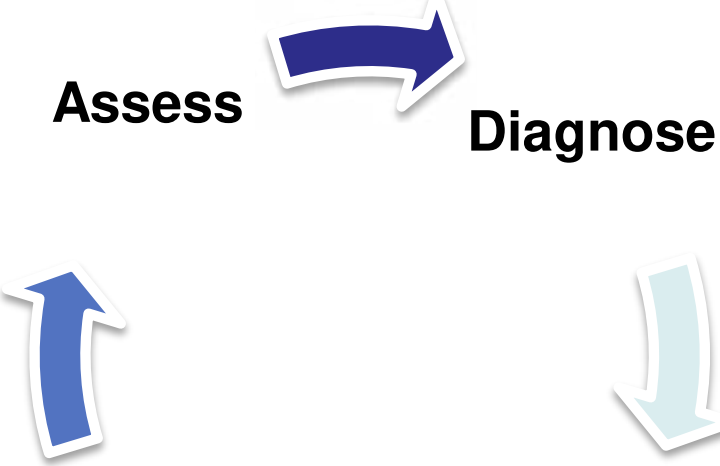

Evaluate

Diagnose
- The NCP includes the International Dietetics and Nutrition Terminology (IDNT); a set of standardized nutrition care terms and definitions [3]

- This model supports consistency in dietetic practice and creates a link between nutrition intervention and expected/actual nutrition outcomes [4-5]

- Documentation practices among Registered Dietitians (RDs) at The Hospital for Sick Children (HSC) varies widely between programs and practitioners

- The need to link clinical care provided by RDs with measurable nutritional outcomes is becoming increasingly important in today's healthcare climate

\section{Results}

- Surveys were completed by all RDs in attendance ( $\mathrm{n}=34$ pre-education, $\mathrm{n}=26$ post-education) to compare baseline with end of training results

- Following education RDs felt they had received sufficient training and felt confident about integrating NCP into their practice $(p<0.05)$

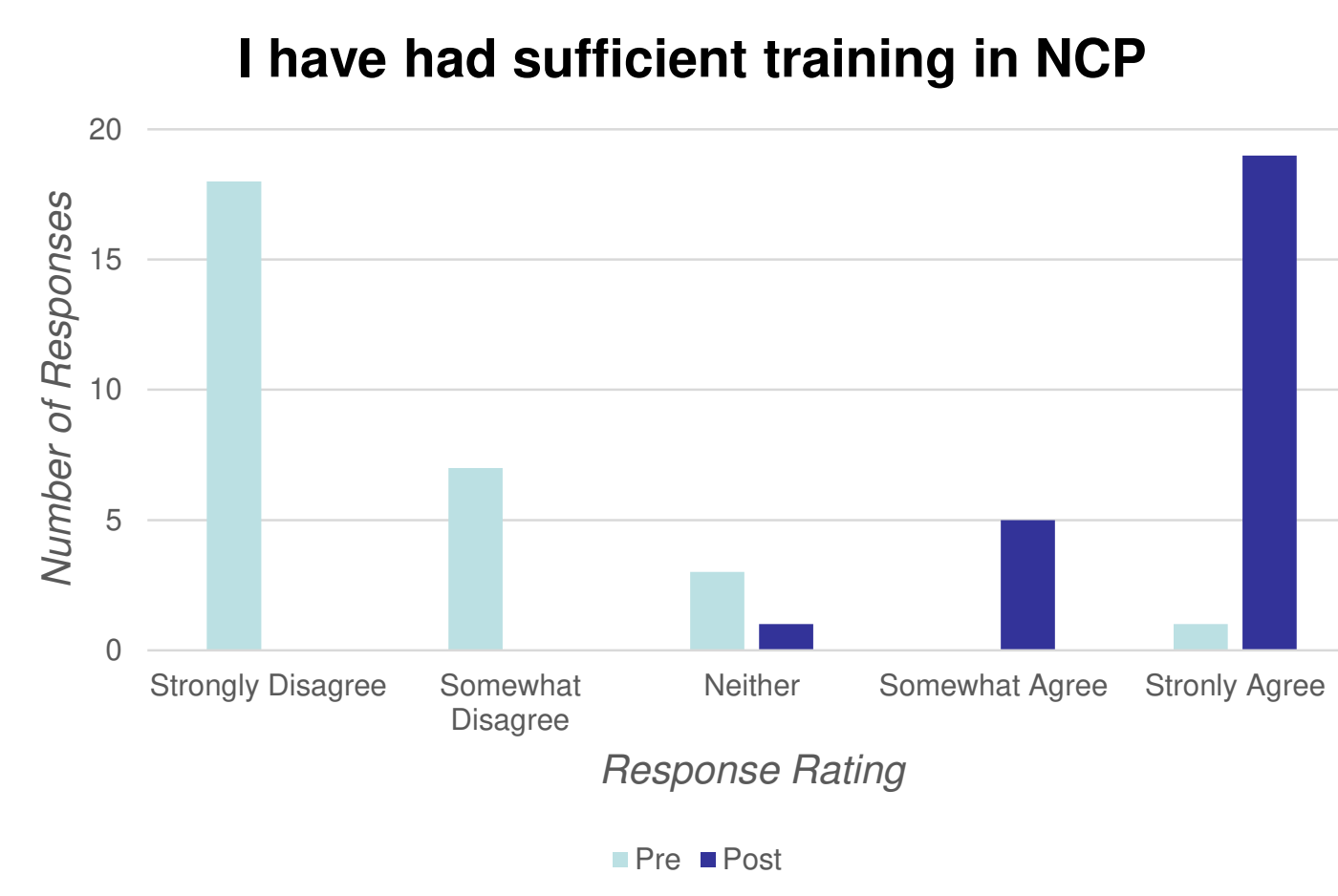

- A decrease in the length of time spent charting was observed $(p<0.05)$

\section{Time Spent Writing Chart Notes}

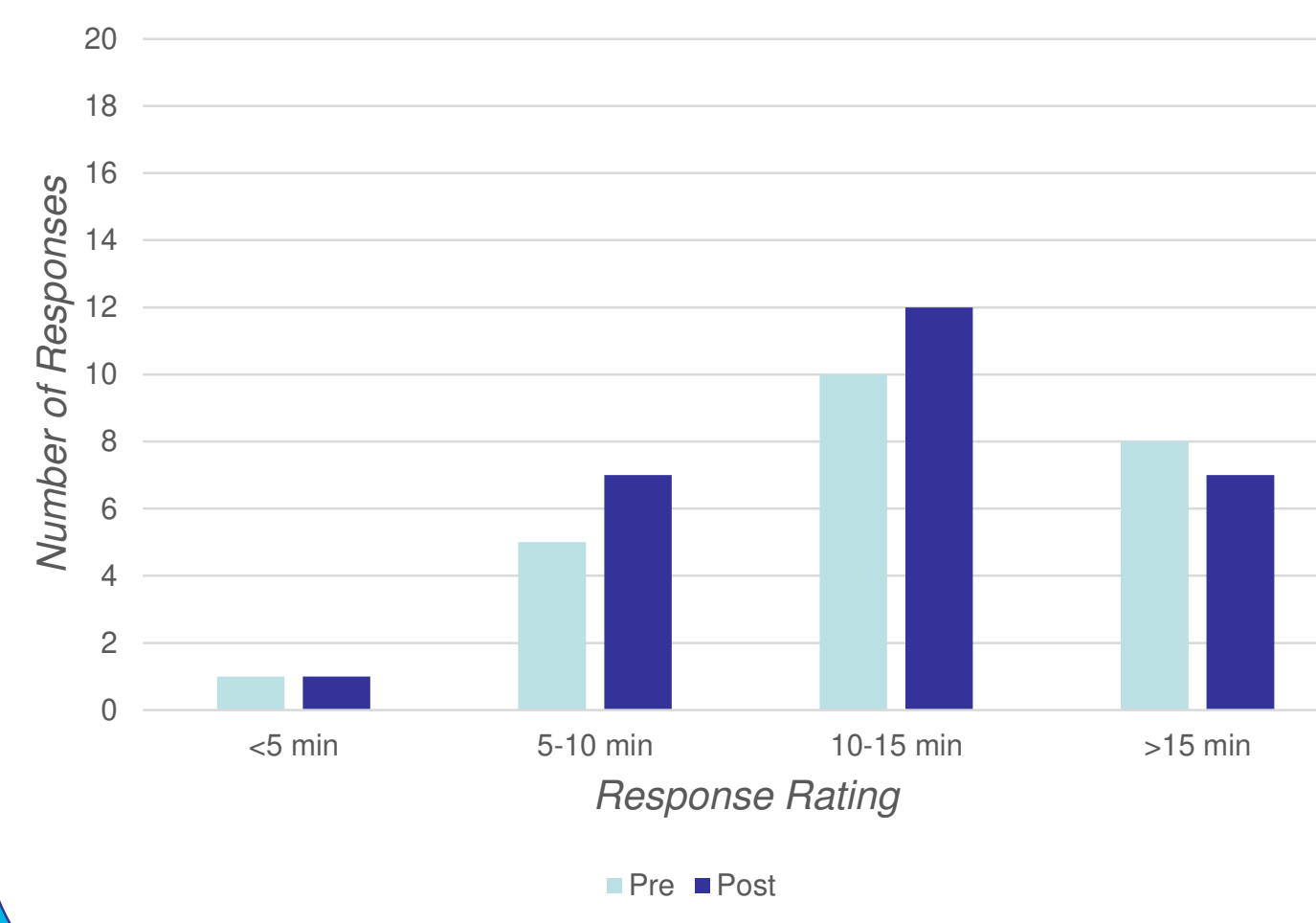

\section{Methods}

- A committee of six RDs was formed to provide education and support the implementation of NCP

- The committee developed and delivered continuous inservice education sessions

- The committee administered pre- and post-education surveys to measure outcomes including adequacy of training and confidence level of adopting NCP

\section{Conclusions}

- NCP was positively received by the RDs at HSC

- RDs provided feedback that the training received was appropriate and they felt confident in their skills

- NCP has been successfully incorporated into RD clinical practice at HSC

References:

1. Desroches S, Lapointe A, Deschenes SM, Gagnon MP. Psychosocial factors and intention to use the nutrition care process among dietitians and dietetic interns. Can J Diet Pract Res. 2014;75(1):e335-41.

2. Dietitians of Canada. Canadian perspectives on the nutrition care process and international dietetics and nutrition terminology; 2010 [cited 2018 Mar 29]. Available from: https://www.dietitians.ca/Downloads/Public/NCP-and-IDNT-Statement-Eng.aspx

3. Van Heukelom H, Fraser V, Koh J, McQueen K, Vogt K, Johnson F. Implementing nutrition diagnosis: At a multisite health care organization. Can J Diet Pract Res. 2011;72:178-180.

4. Lacey K, Pritchett E. Nutrition care process and model: ADA adopts a road map to quality care and outcomes management. J Am Diet Assoc. 2003;103(8):1061-72.

5. Mathieu J, Foust M, Ouellette P. Implementing nutrition diagnosis, step two in the nutrition care process and model: challenges and lessons learned in two health care facilities. J Am Diet Assoc. 2005;105(10):1636-40. 